\title{
The role of genetic factors in the pathogenesis of neonatal intraventricular hemorrhage
}

\author{
Dawid Szpecht ${ }^{1}$, Marta Szymankiewicz ${ }^{1}$, Agnieszka Seremak-Mrozikiewicz ${ }^{2}$, Janusz Gadzinowski ${ }^{1}$ \\ ${ }^{1}$ Department of Neonatology, Poznan University of Medical Sciences, ${ }^{2}$ Department of Perinatology and Women's Diseases, \\ Poznan University of Medical Sciences, Poznan, Poland
}

\begin{abstract}
Intraventricular hemorrhage (IVH) affects 15-20\% of babies born before 32 weeks of pregnancy. Besides gestational age (below 32 weeks) there are a number of IVH risk factors. Increasing attention is being paid to genetic factors in the development of IVH. The authors discuss genetic factors (mutations of coagulation factors, gene polymorphisms in pro-inflammatory cytokines, mutation of type IV collagen gene, polymorphisms of genes responsible for the regulation of systemic blood pressure and cerebral blood flows) whose involvement in IVH pathogenesis has been confirmed in the highest number of reports and for which being a carrier plays an important role in their pathophysiology. The role of genetic factors in IVH remains unclear. Further analysis of the role of genetic factors in the pathophysiology of IVH will make it possible to determine the group of newborns who are specifically at risk of developing IVH in the perinatal period.
\end{abstract}

Key words: neonatal intraventricular hemorrhage, genetic factors, pathophysiology.

Intraventricular hemorrhage (IVH) is a condition which mainly affects prematurely born infants. It affects $15-20 \%$ of babies born before 32 weeks of pregnancy. The condition rarely occurs in full-time infants. About $90 \%$ of cases of intraventricular hemorrhage occur within the first 3 days of the newborn's life. In $20-40 \%$ of cases the spread of the initial bleeding becomes more extended, which is most often observed at the end of the first week of life. In the majority of cases involving mild bleeding (classified as grades 1 and 2) no clinical effects are observed. Grade 3 or 4 hemorrhage may manifest itself in a sudden deterioration in the clinical condition, seizures, consciousness disorders and neurological symptoms, such as eye movement disorders, decreased spontaneous movement, and muscle tone disturbances. Grade 1 and 2 hemorrhages usually resolve themselves and cause no long-term problems. About $40-80 \%$ of newborns with grade 3 or 4 hemorrhages develop symptoms of cerebral palsy [25].

Besides gestational age (below 32 weeks) and body weight at birth (less than $1500 \mathrm{~g}$ ) there are also other IVH risk factors identified in the literature, including: absence of prenatal steroid therapy in women at risk of premature delivery, early clamping of the umbilical cord (up to 30 seconds after birth), symptoms of intrauterine infection in the mother and the newborn, and labor and delivery complicated by bleeding or perinatal hypoxia. The group of infants with elevated IVH risk also includes 
newborns with intrauterine growth retardation, and those who in the first days of their life were treated with crystalloids (bolus 10-15 ml/kg) and/or catecholamines for hypotension and $\mathrm{NaHCO}_{3}$ for acidosis. The IVH risk group also includes newborns with blood clotting disorders, thrombocytopenia, hypoglycemia, pneumothorax, bleeding of lungs, and those transported from another hospital $[3,4,27]$. Moreover, today increasing attention is being paid to genetic factors in the development of IVH, but their connection with IVH in the newborn has been confirmed by few clinical studies so far. The purpose of this paper is to discuss those genetic factors whose involvement in IVH pathogenesis has been confirmed in the highest number of reports and for which being a carrier plays an important role in their pathophysiology.

\section{Congenital thrombophilias: factor V Leiden gene mutation, prothrombin G20210A mutation, factor XIII Val34Leu polymorphism}

Congenital thrombophilias are a genetically conditioned predisposition for venous or arterial thrombosis. Activated protein $C$ resistance (APCR), i.e. the resistance of factor $\mathrm{V}$ to the anti-coagulant action of APC, is the most prevalent type of congenital thrombophilia, and in over $90 \%$ of patients it is caused by a point mutation of the factor $V$ gene on chromosome 1 (the Leiden mutation).

Factor $\mathrm{V}$ (FV) is synthesized by hepatocytes. It is also created in monocytes, macrophages and megakaryocytes, and is transformed by thrombin to its active form (factor $\mathrm{Va}$, FVa). Factor $\mathrm{V}$ undergoes thrombin-dependent activation and APC-dependent inactivation. Thrombin cleaves FV at Arg709, Arg1018 and Arg1545 within the B domain of FV. The result is the active form (FVa) which, together with FXa and calcium ions, forms the prothrombinase complex that converts prothrombin into thrombin. Besides its pro-coagulant activity, FVa also plays an anti-coagulant role (APC-dependent). APC-mediated proteolysis of FVa to FVi occurs when APC is attached to FVa at Arg306, Arg506 and Arg679 of the heavy chain of FVa. The role of FVa is also to inactivate FVIIIa to FVIIIi, which is initiated by connecting APC to FVa at Arg506 and forming FVac, which inactivates FVIIIa $[9,28,34]$.

Factor $\mathrm{V}$ Leiden mutation is an autosomal dominant genetic mutation affecting between $2 \%$ and
$10 \%$ of the Caucasian race. This form of mutation is most often encountered in Cyprus, southern Sweden, Germany, Saudi Arabia and among the Jewish community in Israel, whereas it is extremely rare in Africa and in the Chinese and Japanese populations. In $90 \%$ of cases of factor $V$ Leiden mutation, arginine at position 506 of the heavy chain is replaced with glutamine, which results in resistance to APC-dependent proteolysis and retained pro-coagulant activity of factor $V$. In addition, the mechanism of FVIIla inactivation by FVac is switched off. In people with heterozygous mutation the risk of thromboembolic disease is 3-8 times higher than it is in the healthy population. In people with homozygous mutation the risk of developing venous thrombosis is even 80 times as high as the general population risk. The most frequently found symptoms of Leiden mutation are superficial thrombophlebitis and deep vein thrombosis of the legs and thrombosis in atypical locations: inferior vena cava, hepatic portal vein, hepatic veins [20,21].

Prothrombin (factor II, FII) is a vitamin K-dependent proenzyme produced in the liver and converting fibrinogen to fibrin. The prothrombin encoding gene is located on chromosome 11 (region: p11-q12). The F2 allelic variant - a mutation in the 3' untranslated region of the prothrombin gene (20210 - changing guanine to adenine) is associated with higher levels of prothrombin synthesis, increasing prothrombin plasma levels by over $10 \%$. Its prevalence in the Polish population is estimated at approx. 1\% [26]. In both child and adult populations an association has been found between the mutation of the prothrombin gene and the incidence of thrombosis in certain venous locations (portal vein, intracranial veins). Being a carrier of both factor $V$ Leiden gene mutation and the prothrombin G20210A mutation increases the risk of thrombotic incidents approx. 3-fold, compared with the factor $V$ Leiden gene mutation alone [31].

The association between the factor $\mathrm{V}$ Leiden gene mutation and IVH was first described in the literature in a group of 8 infants with hydrocephalus. Due to the immaturity of anti-coagulation mechanisms, including the C-protein system (comprising the $C$ protein, $S$ protein and thrombomodulin), the newborn shows a tendency to over-coagulate. The roles of factor $\mathrm{V}$ Leiden gene mutation and the prothrombin gene in IVH pathogenesis are probably a consequence of an increased risk of thrombosis in 
the fine blood vessels in the region of the germinal matrix. Increased blood pressure in germinal matrix vessels may lead to vessel wall rupture and to IVH. As reported in the literature, congenital thrombophilia is associated with an increased IVH risk among newborns, but it may also play a protective role. Petäjä et at. [31] analyzed a group of 51 newborns with very low weight at birth (22 infants with grade 2 to 4 IVH and 29 in the control group), in which IVH was observed among carriers of the factor $V$ Leiden gene mutation. Similar conclusions were reached by Komlósi et al. [18], who observed an increased IVH risk in newborns with congenital thrombophilia and birth weight below 2500 g. However, there are other studies which indicate that factor $V$ Leiden and prothrombin G20210A gene mutations have a protective role against IVH. Data published by Göpel et al. [12] show that the risk of IVH above grade 2 among infants carrying factor $\mathrm{V}$ Leiden and prothrombin G20210A gene mutations is lower than among those not carrying these mutations. Härtel et al. [14] found no association between the prevalence of IVH in infants with body weight at birth < $1500 \mathrm{~g}$ and being the carrier of these mutations. Thus, the role of factor $V$ Leiden and prothrombin G20210A gene mutations in the pathogenesis of $\mathrm{IVH}$ remains unclear. The heterogeneity, size and ethnic diversity of the groups of infants studied provide the most likely explanation of the differences in findings concerning the role of these two mutations in IVH pathogenesis.

The role of other genetic factors, such as factor XIII-Val34Leu polymorphism and factor VII-323 del/ ins polymorphism, in the pathogenesis of neonatal IVH has not been fully confirmed. Factor XIII, whose role is to stabilize fibrin and create a clot, is coded by a gene located on chromosome 6 . A point mutation in codon 34 at exon 2 of the factor XIII A subunit results in substituting leucine for valine at position 34 of the peptide. As reported in the literature, in the adult population the polymorphic variant of factor XIIIVal34Leu protects against myocardial infarction, ischemic stroke and venous thromboembolism while at the same time increasing the risk of intracranial hemorrhage [17]. Göpel et al. [11] confirmed an increased frequency of IVH grade 1 to 4 in very low birth weight infants carrying the Leu/Val or Leu/Leu allele $(14.3 \%)$, compared to those with the Val/Val allele (10.1\%). This association was not confirmed by Härtel et al. [14].

\section{Gene polymorphisms in pro-inflammatory cytokines}

There is no doubt that factors involved in inflammatory processes play a role in the pathogenesis of IVH. The role of a number of pro-inflammatory cytokines and polymorphic variants of IL-1 $\beta$, ESR1 and TNF- $\alpha$ genes and their impact on damage to an immature central nervous system and the development of IVH in pre-term infants has been investigated in many studies $[7,16,23,26,37]$.

Interleukin 1 (IL-1) is a family of cytokines comprising over 10 molecules including IL-1 $\alpha, \mathrm{IL}-1 \beta, \mathrm{IL}-1 \gamma$

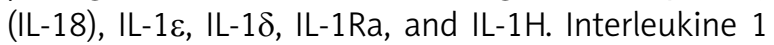
plays a major role in regulating an inflammatory reaction and is produced mainly by monocytes and macrophages of various tissues in response to bacterial, viral and fungal antigens. The majority of IL-1

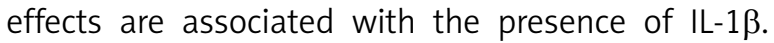
A significant association was confirmed between an increased IL-1 $\beta$ concentration in the amniotic fluid and umbilical cord blood and the development of IVH and periventricular leukomalacia in neonates [37]. Animal tests proved that administration of IL- $1 \beta$ causes damage to the central nervous system of newborn rats, yet the pathology mechanism is still unknown [7]. In 2013 Adén et al. [2] presented the results of a study in which genotypes of 224 premature infants with birth weight between 500 and $1250 \mathrm{~g}$ and with IVH grade 3 and 4 were analyzed. The analysis covered a number of gene polymorphisms for collagen 4A1 (COL4A1 Gly1580Arg); FII (97 G>A); FV (1601 G>A); interleukin IL-1B(87-511 T>C;87-31C $>T)$; interleukin 6 (116-121 C>G); methylenetetrahydrofolate reductase (MTHFR) (677 C>T; 1298 A>C); TNF (169-319 G>A). In the study, of a number of the polymorphisms analyzed, the role in the pathogenesis of IVH was confirmed in carriers of the MTHFR 1298 A $>C$ gene polymorphism, more frequently with the CC genotype. MTHFR is an enzyme which catalyzes the reduction of 5,10-methylenetetrahydrofolate to 5-methyltetrahydrofolate, a substrate in remethylation of homocysteine to methionine. Mutations in the MTHFR gene cause a reduction in the enzyme activity, which results in increased blood plasma homocysteine concentration. Raised homocysteine levels may cause damage to vascular endothelium, increase the risk of vessel rupture and lead to IVH.

Tumor necrosis factor (TNF) is produced mainly by active monocytes and macrophages and, in much lower quantities, by other tissues, and - together 
with interleukins 1 and 6 - plays a role in the localized and systemic inflammatory response, using endo-, para- and autocrine signaling to communicate with immune system cells. Tumor necrosis factor is thought to play a role in the growth, differentiation and activities of various cells, both normal and modified by cancer. Among other things, it is responsible for damage to microcirculatory endothelium in the central nervous system, thereby increasing the risk of vessel rupture and IVH occurrence. The role of specific polymorphic gene variants for TNF- $\alpha$ and TNF- $\beta$ in the pathogenesis of neonatal IVH is unclear. Adcock et al. [1] found a correlation between the development of IVH and being a carrier of the TNF- $\alpha 308$ G/A (allele A) polymorphism. In a study investigating the role of polymorphic gene variants of $308 \mathrm{G} / \mathrm{A}$ TNF- $\alpha$ and Ncol TNF- $\beta$ in a group of 27 infants born before week 32 of pregnancy, Heep et al. [15] confirmed higher incidence of severe (grade 3 or 4) IVH in carriers of the TNF- $\beta 2$ allele, while a corresponding correlation in carriers of a polymorphism of the -308 promoter region of the TNF- $\alpha$ gene was not found.

\section{Mutation of type IV collagen gene}

The COL4A1 gene encodes the $\alpha$ chain of type IV collagen. Type IV collagen is the principal component of basement membrane. In mice studies the mutation in the COL4A1 gene resulted in intracranial hemorrhage, including IVH. The literature indicates that the 4582-4586dupCCCATG mutation of the COL4A1 gene is related to neonatal porencephaly and hemorrhagic stroke in adults. In 2009, Bilguvar et al. [5] published results which indicate the role of the 4582-4586dupCCCATG mutation of the COL4A1 gene in the pathogenesis of IVH in preterm infants. The 4582-4586dupCCCATG variant of the COL4A1 mutation leads to the insertion of two amino acids in the NC1 domain of type IV collagen, which results in destabilization of collagen IV and in perforation of the vascular basement membrane which affects, inter alia, cerebral vessels of newborn infants [5].

\section{Polymorphisms of genes responsible for regulation of systemic blood pressure and cerebral blood flows}

Cerebral blood flows through an infant's brain are controlled by four mechanisms: autoregulation and chemical, metabolic and neurogenic regulation. In healthy infants born at term the regulation of cerebral blood flow responds to stimuli in the same way as it does in an adult. Cerebral blood vessels, with their rich innervation (both sympathetic and parasympathetic), respond by contracting to neurotransmitters such as noradrenaline, serotonin and neuropeptide $\mathrm{Y}$, and by relaxation to acetylcholine, vasoactive intestinal peptide and nitric oxide. In the pathogenesis of neonatal IVH in preterm infants, an important role is played by changes in venous and arterial cerebral flows. It has been shown that the ability of autoregulation of cerebral flows in response to variations in arterial blood pressure in preterm infants is impaired. This impaired autoregulation causes an increased risk of germinal matrix rupture and IVH occurrence [6].

It seems that endothelial nitric oxide synthase (eNOS) gene polymorphisms (Glu298Asp or -786 $\mathrm{T}>\mathrm{C}$ ) may increase the risk of IVH in preterm infants by significantly disrupting the regulation of cerebral flows $[6,35]$. Nitric oxide (NO) is continuously synthesized in the human body, inter alia in vascular endothelium. It is synthesized from the guanidine group of L-arginine with the release of L-citrulline in a reaction catalyzed by eNOS in the presence of molecular oxygen and cofactors: reduced nicotinamide adenine dinucleotide phosphate (NADPH), flavin adenine dinucleotide (FAD) and tetrahydrobiopterin (BH4). The eNOS enzyme, taking up cellular membrane microdomains in cells such as endothelium, myocytes, platelets and neurons, plays an important role in the transduction of signals reaching the cell from outside, e.g. by interaction with caveolin-1. The eNOS activity is controlled, inter alia, by phosphorylation and depalmitoylation, binding to the $\mathrm{Ca}^{2+} /$ calmodulin complex, and association with the Hsp90 protein. NO synthesis disorders may result from genetically conditioned disruptions in eNOS activity. The NOS3 gene (eNOS coding gene) comprises 26 exons and 25 introns; it codes 1203 amino acids with molecular mass of $133 \mathrm{kDa}$. The NOS3 gene polymorphism whereby guanine (G) is replaced with thymine (T) at nucleotide 894 (exon 7) results in a change of the amino acid sequence of Glu298Asp. The 786 T>C polymorphism of the NOS3 gene replaces thymine with cytosine in the NOS3 gene promoter at -786 . It is thought that in the presence of Glu298Asp and -786T>C polymorphic variants, eNOS enzymatic activity may be impaired. The main NO receptor is guanyl cyclase. The effect of guanyl cyclase activation is an increase in cGMP 
levels and the activation of protein kinase G (PKG). In endothelium NO plays a central role in the regulation of local blood pressure, by acting as a vasodilatory agent, whereby it ensures that blood flow through the tissues is adequate to the requirements. Moreover, it counteracts the factors acting as strong vasoconstrictive agents, such as endothelin- 1 and angiotensin II, and it inhibits aggregation and adhesion of blood platelets by reducing the production of platelet activation factor (PAF) by the endothelium. It also acts protectively for vessel walls, by inhibiting oxidation of lipids and inactivating oxygen free radicals [10]. It has also been demonstrated that in pregnant women the activity of the NO synthesis system is high. This activity decreases as the delivery term approaches, which plays a major role in the mechanism of stimulating uterine contractions and the start of labor. Elevated levels of nitric oxide during pregnancy result from the stimulation of NO synthase in the uterine muscle and the syncytiotrophoblast by high estradiol concentrations. Maternal levels of NO also regulate the resistance in uteroplacental circulation vessels. NO deficiency in pregnancy may be related to arrested intrauterine fetus development and low birth weight. In infants carrying polymorphic variants of the eNOS gene a decreased concentration of nitric oxide synthase may lead to lower NO concentration in the perinatal period and to disruptions affecting neonatal cerebral blood flows $[24,29,30]$.

The renin-angiotensin-aldosterone system (RAA system/RAAS) is a system that regulates blood volume and blood pressure, as well as the concentration of $\mathrm{Na}$ and $\mathrm{K}$ ions in systemic fluids.

Deletion/insertion variant for the angiotensin converting enzyme (ACE ins/del) and the 1166A/C polymorphism of 1 Ang II (ATR1166A/C) are related to a better prognosis in the course of acute respiratory distress syndrome. The role of these two polymorphisms in the IVH pathology in newborns still remains unclear. It is reported in the literature that the polymorphism of the ACE ins/del gene may act as either a good or a bad prognostic factor in the course of the infant respiratory distress syndrome. Newborn infants carrying the ACE ins/ del polymorphism also carry a higher risk of retinopathy of prematurity (ROP), and those carrying ATR1166A/C polymorphism carry a risk of persistent ductus arteriosus (PDA) in premature infants [13]. In 2011 Spiegler et al. [32] published the results of a multi-center study carried out on 1209 infants born with body weight below $1500 \mathrm{~g}$ in 12 centers in Germany. No significant association between ACE-ins/del or ATR1166A/C genotype and neonatal death or other infant outcome parameters (such as IVH, bronchopulmonary dysplasia, ROP or PDA) was found $[32,36]$.

Research to date has shown that the polymorphic variants of the ET-1 gene Lys198Asn and 134delA play a significant role in the pathogenesis of ischemic heart disease and arterial hypertension in adults, including in pregnancy, while their impact on the development of neonatal IVH is unclear. Endothelin 1 (ET-1) is the strongest known vasoconstrictor - the vasospasm effect lasts for 45-60 minutes. Endothelin 1 may play a role in maintaining hemodynamic homeostasis by changing the distribution of blood in the system [33]. It is also reported in the literature that childbirth is a stress factor leading to increased synthesis of ET-1 by umbilical vein endothelium. Endothelin 1 may play a significant role in the regulation of blood flow through the feto-placental unit. It is suggested that the fetus itself also synthesizes the hormone, as a result of hemodynamic and metabolic changes occurring during uterine contractions in childbirth. It is likely that an increased concentration of ET-1 in umbilical blood plasma during childbirth leads to the contraction of umbilical vessels after delivery, and it may be one of the mechanisms that prepare the fetus for taking the first breath [22].

Intraventricular hemorrhage represents a very significant complication in preterm infants. The role of genetic factors in IVH remains unclear. Further analysis of the role of genetic factors in the pathophysiology of IVH will make it possible to determine the group of newborns who are specifically at risk of developing IVH in the perinatal period.

\section{Disclosure}

Authors report no conflict of interest.

\section{References}

1. Adcock K, Hedberg C, Loggins J, Kruger TE, Baier RJ. The TNFalpha-308, MCP-1 -2518 and TGF-beta-1 +polymorphisms are not associated with the development of chronic lung disease in very low birth weight infants. Genes Immun 2003; 4: 420-426.

2. Adén U, Lin A, Carlo W, Leviton A, Murray JC, Hallman M, Lifton RP, Zhang H, Ment LR; Gene Targets for Intraventricular Hemorrhage Study Group. Gene Targets for Intraventricular Hemorrhage Study Group. Candidate gene analysis: severe 
intraventricular hemorrhage in inborn preterm neonates. J Pediatr 2013; 163: 1503-1506.

3. Allen KA. Treatment of hemorrhages in premature infants: where is the evidence? Adv Neonatal Care 2013; 13: 127-130.

4. Bassan $\mathrm{H}$. Intracranial hemorrhage in the preterm infant: understanding it, preventing it. Clin Perinatol 2009; 36: 737-762.

5. Bilguvar K, DiLuna ML, Bizzarro MJ, Bayri Y, Schneider KC, Lifton RP, Gunel M, Ment LR; Pacifier and Breastfeeding Trial Group. COL4A1 mutation in preterm intraventricular hemorrhage. J Pediatr 2009; 155: 743-745.

6. Brinker T, Stopa E, Morrison J, Klinge P. A new look at cerebrospinal fluid circulation. Fluids Barriers CNS 2014; 11: 10.

7. Cai Z, Pang Y, Lin S, Rhodes PG. Differential roles of tumor necrosis factor-alpha and interleukin-1 beta in lipopolysaccharide-induced brain injury in the neonatal rat. Brain Res 2003; 975: 37-47.

8. Demirçubuk AG, Coşkun MY, Demiryürek Ş, Dokuyucu R, Öztuzcu S, Taviloğlu ZŞ, Arslan A, Sivaslı E. Endothelial NOS gene Glu298Asp polymorphism in preterm neonates with respiratory distress syndrome. Pediatr Pulmonol 2013; 48: 976-980.

9. Esmon CT. Crosstalk between inflammation and thrombosis. Maturitas 2008; 61: 122-131.

10. Galluccio E, Cassina L, Russo I, Gelmini F, Setola E, Rampoldi L, Citterio L, Rossodivita A, Kamami M, Colombo A, Alfieri O, Cari ni M, Bosi E, Trovati M, Piatti P, Monti LD, Casari G. A novel truncated form of eNOS associates with altered vascular function. Cardiovasc Res 2014; 101: 492-502.

11. Göpel W, Kattner E, Seidenberg J, Kohlmann T, Segerer H, Möller J; Genetic Factors in Neonatology Study Group. The effect of the Val34Leu polymorphism in the factor XIII gene in infants with a birth weight below 1500 g. Pediatr 2002; 140: 688-692.

12. Göpel W, Gortner L, Kohlmann T, Schultz C, Möller J. Low prevalence of large intraventricular hemorrhage in very low birth weight infants carrying the factor $V$ Leiden or prothrombin G20210A mutation. Acta Paediatr 2001; 90: 1021-1024.

13. Harding D, Dhamrait S, Marlow N, Whitelaw A, Gupta S, Humphries S, Montgomery $\mathrm{H}$. Angiotensin-converting enzyme DD genotype is associated with worse perinatal cardiorespiratory adaptation in preterm infants. J Pediatr 2003; 143: 746-749.

14. Härtel C, König I, Köster S, Kattner E, Kuhls E, Küster H, Möller J, Müller D, Kribs A, Segerer H, Wieg C, Herting E, Göpel W. Genetic polymorphisms of hemostasis genes and primary outcome of very low birth weight infants. Pediatrics 2006; 118: 683-689.

15. Heep A, Schueller AC, Kattner E, Kroll M, Sander J, Wisbauer M, Bartmann P, Stueber F. Association of two tumour necrosis factor gene polymorphisms with the incidence of severe intraventricular haemorrhage in preterm infants. J Med Genet 2005; 42 604-608.

16. Kadhim H, Tabarki B, Verellen G, De Prez C, Rona AM, Sebire G. Inflammatory cytokines in the pathogenesis of periventricular leukomalacia. Neurology 2001; 56: 1278-1284.

17. Kohler HP, Stickland MH, Ossei-Gerning N, Carter A, Mikkola H, Grant PJ. Association of a common polymorphism in the factor XIII gene with myocardial infarction. Thromb Haemost 1998 ; 79: 8-13.

18. Komlósi K, Havasi V, Bene J, Storcz J, Stankovics J, Mohay G, Weisenbach J, Kosztolányi G, Melegh B. Increased prevalence of factor $\mathrm{V}$ Leiden mutation in premature but not in full-term infants with grade I intracranial hemorrhage. Biol Neonate 2005; 87: 56-59.

19. Kosińska-Kaczyńska K, Szymusik I, Kaczyński B. Jatrogenne i samoistne późne wcześniactwo wśród bliźniąt a ryzyko powikłań noworodkowych. Ginekol Pol 2013; 84: 430-435.

20. Laurent OM, Berislav VZ, Griffin JH. The cytoprotecive protein C pathway. Blood 2007; 109: 3161-3172.

21. Lewandowski K, Turowiecka Z, Rozek M, Markiewicz WT, Zawilska K. Mutacja punktów GàA nukleotydów 1691 genu czynnika $\vee$ przyczyną powikłań zakrzepowych w rodzinie z opornością osocza na działanie aktywnego białka C. Pol Arch Med Wewn 1996; 4: 318-322.

22. Lisi V, Paternoster DM, Stecca A, Micciché F, Fantinato S, Leon A, Damante G, Fabbro D, Clementi M. Investigation of endothelin-1 type A receptor gene polymorphism (-231 G/A) in preeclampsia susceptibility. J Matern Fetal Neonatal Med 2007; 20: 145149

23. Liu XH, Kwon D, Schielke GP, Yang GY, Silverstein FS, Barks JD. Mice deficient in interleukin-1 converting enzyme are resistant to neonatal hypoxic-ischemic brain damage. J Cereb Blood Flow Metab 1999; 19: 1099-1108.

24. Pappa KI, Roubelakis M, Vlachos G, Marinopoulos S, Zissou A, Anagnou NP, Antsaklis A. Variable effects of maternal and paternal-fetal contribution to the risk for preeclampsia combining GSTP1, eNOS, and LPL gene polymorphisms. J Matern Fetal Neonatal Med 2011; 24: 628-635.

25. Payne AH, Hintz SR, Hibbs AM, Walsh MC, Vohr BR, Bann CM, Wilson-Costello DE; Eunice Kennedy Shriver National Institute of Child Health and Human Development Neonatal Research Network. Neurodevelopmental outcomes of extremely low-gestational-age neonates with low-grade periventricular-intraventricular hemorrhage. JAMA Pediatr 2013; 167: 451-459.

26. Petäjä J, Hiltunen L, Fellman V. Increased risk of intraventricular hemorrhage in preterm infants with thrombophilia. Pediatr Res 2001; 49: 643-646.

27. Rosendorff A, Dorfman DM. Activated Protein C Resistance and Factor V Leiden. Arch Pathol Lab Med 2007; 131: 866-871.

28. Ryckman KK, Dagle JM, Kelsey K, Momany AM, Murray JC. Replication of genetic associations in the inflammation, complement, and coagulation pathways with intraventricular hemorrhage in LBW preterm neonates. Pediatr Res 2011; 70: 90-95.

29. Seremak-Mrozikiewicz A, Drews K, Barlik M, Sieroszewski P, Grześkowiak E, Mrozikiewicz P. The significance of -786T > C polymorphism of endothelial NO synthase (eNOS) gene in severe preeclampsia. J Matern Fetal Neonatal Med 2011; 24: 432-436.

30. Seremak-Mrozikiewicz A, Drews K, Mrozikiewicz PM. The $-786 \mathrm{~T} / \mathrm{C}$ polymorphism of the endothelial nitric oxide synthase gene in preeclampsia. Eur J Obstet Gynecol Reprod Biol 2008; 138: 118-119.

31. Skrzypczak J, Rajewski M, Wirstlein P, Goździewicz T, Breborowicz G, Leszczyńska-Gorzelak B, Ludwikowski G, Preis K, Wołczyński S, Zimmer M. Incidence of hereditary thrombophilia in women with pregnancy loss in multi-center studies in Poland. Ginekol Pol 2012; 83: 330-336.

32. Spiegler J, Gilhaus A, Konig IR, Kattner E, Vochem M, Kuster H, Moller J, Muller D, Kribs A, Segerer H, Wieg C, Nikischin W, von 
der Wense A, Gebauer C, Herting E, Gopel W. Polymorphisms in the Renin-Angiotensin system and outcome of very-low-birthweight infants. Neonatology 2010; 97: 10-14.

33. Su MT, Lin SH, Chen YC. Genetic association studies of angiogenesis- and vasoconstriction-related genes in women with recurrent pregnancy loss: a systematic review and meta-analysis. Hum Reprod Update 2011; 17: 803-812.

34. Szpecht D, Poprawski G, Mrówczyński W. The activity of protein $C$ in infants undergoing cardiopulmonary bypass to correct a congenital heart defect - a pilot study. Adv Clin Exp Med 2009; 18: 163-168.

35. Vannemreddy P, Notarianni C, Yanamandra K, Napper D, Bocchini J. Is an endothelial nitric oxide synthase gene mutation a risk factor in the origin of intraventricular hemorrhage? Neurosurg Focus 2010; 28: E11.

36. Yanamandra K, Loggins J, Baier RJ. The Angiotensin Converting Enzyme Insertion/Deletion polymorphism is not associated with an increased risk of death or bronchopulmonary dysplasia in ventilated very low birth weight infants. BMC Pediatr 2004; 4: 26.

37. Yoon BH, Jun JK, Romero R, Park KH, Gomez R, Choi JH, Kim IO. Amniotic fluid inflammatory cytokines (interleukin-6, interleukin-1beta, and tumor necrosis factor-alpha), neonatal brain white matter lesions, and cerebral palsy. Am J Obstet Gynecol 1997; 177: 19-26. 